\title{
Urinary sodium/potassium ratio as a screening tool for hyperaldosteronism in men with hypertension
}

\author{
Hiroyoshi Segawa ${ }^{1,2} \cdot$ Akane Higashi $^{1} \cdot$ Izuru Masuda $^{3} \cdot$ Kengo Yoshii $^{4} \cdot$ Toshiyuki Iwahori $^{5} \cdot$ Hirotsugu Ueshima $^{2,5}$
}

Received: 4 August 2020 / Revised: 19 March 2021 / Accepted: 21 March 2021 / Published online: 17 May 2021

(c) The Author(s) 2021. This article is published with open access

\begin{abstract}
Among individuals with hypertension, the prevalence of secondary hypertension has been reported to be $\approx 10 \%$. More than half of individuals with secondary hypertension have associated hyperaldosteronism. However, given the current clinical environment, these patients often remain undiagnosed. We hypothesized that the urinary sodium/potassium ratio $(\mathrm{Na} / \mathrm{K})$ could be used as a simple, low-cost method of screening for hyperaldosteronism among individuals with hypertension in primary care and health examination settings. We recruited hypertensive individuals aged 30-69 years old who were not taking any antihypertensive medications from among participants in health examinations. Urinary $\mathrm{Na}$ and $\mathrm{K}$ were measured using second morning urine samples, and the plasma aldosterone concentration (PAC) was also measured. We evaluated the association of the second morning urine $\mathrm{Na} / \mathrm{K}$ ratio (SMU Na/K) with a high PAC, defined as $\geq 90$ th percentile $(24.3 \mathrm{ng} / \mathrm{dL}$ ), using receiver operating characteristic (ROC) curves. Overall, 160 participants (108 men and 52 women) with a mean age of 54.3 years were eligible for this study. The area under the ROC curve for the relationship between SMU Na/K and high PAC was 0.77 (95\% confidence interval [CI]: 0.59-0.95) in men and 0.64 (95\% CI: 0.36-0.93) in women. In men, SMU Na/K values $<1.0$ could detect hyperaldosteronism with a sensitivity of $45.5 \%$, a specificity of $97.9 \%$, a positive predictive value of $71.4 \%$, and a negative predictive value of $94.1 \%$. The use of the urinary $\mathrm{Na} / \mathrm{K}$ ratio may be appropriate as a method of screening for hyperaldosteronism in hypertensive men.
\end{abstract}

Keywords Hyperaldosteronism $\cdot$ Hypertension $•$ Urinary sodium/potassium ratio

\section{Introduction}

Aldosterone is a mineralocorticoid hormone that regulates blood pressure and sodium (Na)-potassium (K) exchange in

Supplementary information The online version contains supplementary material available at https://doi.org/10.1038/s41440021-00663-9.

Akane Higashi

higashi-akane@kpu.ac.jp

1 Graduate School of Life and Environmental Sciences, Kyoto Prefectural University, Kyoto, Japan

2 Center for Epidemiologic Research in Asia, Shiga University of Medical Science, Shiga, Japan

3 Takeda Hospital Medical Examination Center, Kyoto, Japan

4 Department of Mathematics and Statistics in Medical Sciences, Kyoto Prefectural University of Medicine, Kyoto, Japan

5 Department of Public Health, Shiga University of Medical Science, Shiga, Japan the distal tubules and collecting ducts of the kidney. Aldosterone affects blood pressure increases, Na reabsorption, and $\mathrm{K}$ excretion. In some diseases, such as primary aldosteronism and renovascular hypertension, aldosterone is inappropriately secreted, which leads to hypertension [1,2]. These conditions are called hyperaldosteronism or aldosterone excess.

The prevalence of primary aldosteronism, a representative cause of hyperaldosteronism, has been reported to be 4.6-16.6\% among individuals with hypertension worldwide [3]. In Japan, the prevalence of secondary hypertension has been reported to be $9.1 \%$; more than half of patients with secondary hypertension have associated hyperaldosteronism [2]. In a meta-analysis, it was reported that patients with primary aldosteronism have a high risk of cardiovascular diseases (CVDs) [4]. Furthermore, hyperaldosteronism is currently considered to be a risk factor for subclinical atherosclerosis, CVD mortality, and all-cause mortality [5-7] regardless of the presence of secondary hypertension. Although hyperaldosteronism is a common cause of antihypertensive treatment resistance [8], it is treatable with 
Fig. 1 Flow diagram of study participant recruitment. We recruited hypertensive individuals aged 30 to 69 years old who were not taking any antihypertensive medications from among participants in health examinations. Overall, 160 participants (108 men and 52 women) were eligible for inclusion in this study

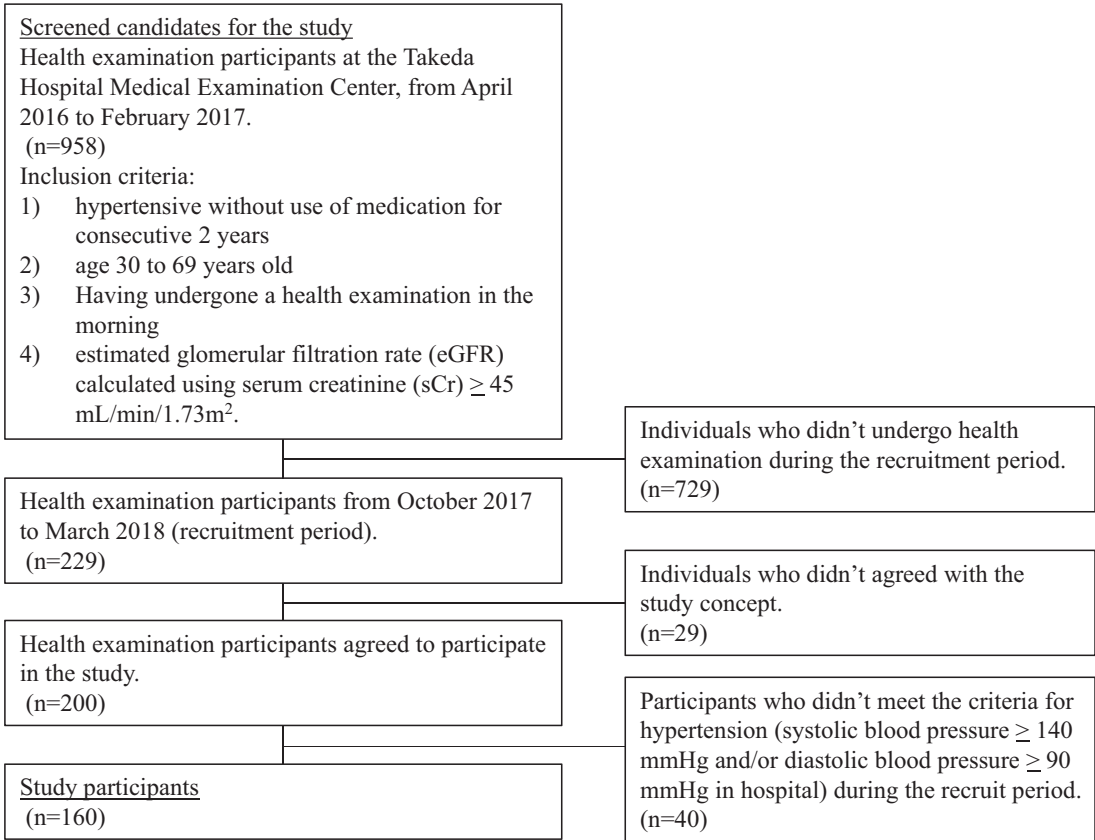

Screened candidates for the study

consecutive 2 years

Having undergone a health examination in the

calculated using serum creatinine $(\mathrm{sCr}) \geq 45$ $\mathrm{mL} / \mathrm{min} / 1.73 \mathrm{~m}^{2}$

examination during the recruitment period.

to March 2018 (recruitment period).
$(\mathrm{n}=229)$

Individuals who didn't agreed with the study concept.

Participants who didn't meet the criteria for hypertension (systolic blood pressure $\geq 140$ $\mathrm{mHg}$ and/or diastolic blood pressure $>90$ $(\mathrm{n}=40)$ specific therapies, such as surgical treatment for aldosterone-producing adenoma and endovascular treatment for renovascular hypertension caused by fibromuscular dysplasia [9]. Mineralocorticoid receptor antagonists can be used as a noninvasive treatment for people with hypertension who have hyperaldosteronism [8]. Thus, early diagnosis and treatment are important for hyperaldosteronism.

Measuring plasma renin activity (PRA) and the plasma aldosterone concentration (PAC) is essential for the detection and classification of hyperaldosteronism. For example, primary aldosteronism is suspected when the PAC/PRA ratio is $>20$ and the PAC is $>12-15 \mathrm{ng} / \mathrm{dL}$, according to the Japanese guidelines for the management of hypertension $[9,10]$. Various methods of identifying primary aldosteronism have been proposed [11, 12]. The Japan Endocrine Society recommends the measurement of PAC and PRA in all patients initially diagnosed with hypertension [10]. However, these measurements are cumbersome and expensive and often omitted in primary care settings, which results in the underdiagnosis of hyperaldosteronism [5]. Thus, easy, practical, and inexpensive screening methods that can be used in primary care or health examination settings are needed.

Because hyperaldosteronism causes excessive $\mathrm{Na}$ reabsorption and $\mathrm{K}$ excretion, we hypothesized that individuals with a high $\mathrm{PAC}$ have a low urinary $\mathrm{Na} / \mathrm{K}$ ratio. Urinary $\mathrm{Na} /$ $\mathrm{K}$ has been used as an indicator of the PAC in the clinical environment [13]. However, the usefulness of the spot urinary $\mathrm{Na} / \mathrm{K}$ ratio for detecting a high PAC has not been evaluated. The aim of this study was to assess whether the urinary $\mathrm{Na} / \mathrm{K}$ ratio can be used to identify individuals with a high PAC from those with hypertension.

\section{Methods}

\section{Participants and measurements}

First, we ascertained the number of candidates for inclusion in the study from among the participants in health examinations at the Takeda Hospital Medical Examination Center from April 2016 to February 2017. Individuals were considered candidates if they met the following criteria: (1) hypertension without the use of medication for two consecutive years, (2) aged 30-69 years old, (3) underwent a health examination in the morning, and (4) available estimated glomerular filtration rate (eGFR) calculated using serum creatinine $(\mathrm{sCr}) \geq 45$ $\mathrm{mL} / \mathrm{min} / 1.73 \mathrm{~m}^{2}$. Second, we sent recruitment documents to candidates who underwent a health examination from October 2017 to March 2018 (recruitment period). As a result, 200 individuals (135 men and 65 women) agreed to participate in our study (Fig. 1). It was confirmed that none of the participants were taking antihypertensive medications. Participants who did not meet the criteria for hypertension (systolic blood pressure $\geq 140 \mathrm{mmHg}$ and/or diastolic blood pressure $\geq 90 \mathrm{mmHg}$ in the hospital) during the recruitment period were excluded from the present study.

The gold standard method for measuring excreted $\mathrm{Na}$ or $\mathrm{K}$ is a 24-h urine collection test. However, this method is cumbersome; therefore, 24-h urinary $\mathrm{Na}$ excretion is often estimated using the concentrations of $\mathrm{Na}$ and creatinine in second morning urine [14]. Similarly, a previous report showed that the urinary $\mathrm{Na} / \mathrm{K}$ ratio in second morning urine is closer to that in 24-h urine than that in 
first morning urine [15]. Therefore, we used the second morning urine $\mathrm{Na} / \mathrm{K}$ ratio (SMU $\mathrm{Na} / \mathrm{K}$ ) in this study. Participants were instructed to void their first morning urine soon after awakening, and second morning urine was collected on-site during their health examination. The $\mathrm{Na} / \mathrm{K}$ ratio in each urine sample was calculated using the $\mathrm{Na}$ and $\mathrm{K}$ concentrations. Laboratory tests associated with the health examination were conducted at the laboratories of Kouseikai Takeda Hospital and Hoken Kagaku Nishi-Nihon. PRA and the PAC were measured using a radioimmunoassay. $\mathrm{Na}$ and $\mathrm{K}$ were assessed using an electrode method, and $\mathrm{sCr}$ was assessed using an enzymatic method. The assay kit used for the measurement of the PAC was the SPAC-S Aldosterone Kit (TFB, Inc. Tokyo, Japan). We calculated the eGFR using the following equation: eGFR $\left(\mathrm{mL} / \mathrm{min} / 1.73 \mathrm{~m}^{2}\right)=194 \times \mathrm{sCr}(\mathrm{mg} / \mathrm{dL})^{-1.094} \times$ $\operatorname{age}^{-0.287} \times 0.739$ (for women) [16]. Blood sampling was performed after $10 \mathrm{~min}$ of rest in a seated position. Baseline blood pressure was measured on-site twice by clinical staff using an automated sphygmomanometer after $10 \mathrm{~min}$ of rest in a seated position. The mean of the two blood pressure measurements was calculated and used for each participant. Body mass index was calculated as the weight divided by the height squared $\left(\mathrm{kg} / \mathrm{m}^{2}\right)$. In the present study, diabetes mellitus was defined as a glycated hemoglobin level of $6.5 \%$ or higher, the use of diabetes medication, or both.

We asked all participants to complete a self-administered questionnaire to collect information regarding hypertension onset, medication, and lifestyle. The intake frequencies for fruit, vegetables, legumes, and salty food were reported by participants, according to the following response options: 3/day, 2/day, 1/day, 3-5/week, 1-2/week, or rarely; the frequency of sweating was also reported according to the following response options: >5/week, 3-4/week, 1-2/week, or rarely. Drinking habits were reported according to the following response options: every day, sometimes, or rarely. Habitual skipping of breakfast ( $\geq 3 /$ week), current smoking, and sweating the day before the examination were reported as yes or no.

\section{Statistical analysis}

First, we described participants' physical characteristics and lifestyles and compared these between men and women. We also described participants' physical characteristics and lifestyles stratified by PAC level ( $\geq$ or $<90$ th percentile value) and compared them separately for each sex. Student's $t$-test was used for continuous variables, and either the chi-square test or Fisher's exact test was used for categorical variables. Second, we assessed the associations of the SMU Na/K and other biologically reasonable variables with the PAC using simple and multiple linear regression analysis. We also evaluated the interactive effect of the SMU Na/K and sex on the PAC. In this analysis, the $\mathrm{SMU} \mathrm{Na/K}$ was $\log$ transformed because of its skewed distribution. Multiple regression analysis model 1 was adjusted for all variables used in the simple linear regression analysis, and multiple regression analysis model 2 was adjusted for variables with $p$ value $<0.10$ in multiple regression analysis model 1 . Third, we used receiver operating characteristic (ROC) curves to explore the relationship between the $\mathrm{SMU} \mathrm{Na/K}$ and a high PAC, defined as $\geq 90$ th percentile. Age and serum K were also added to the logistic regression model used to generate the ROC curves to assess the impact of those covariates. We identified a reasonable cutoff point for the SMU Na/K for the detection of individuals with a high PAC. We then evaluated the sensitivity and specificity of the SMU Na/K using this cutoff point. As a sensitivity analysis, we performed a ROC curve analysis from which we excluded 16 participants who had low levels of sodium excretion ( $\leq 10$ th percentile value) using the Kawasaki equation [14]. Analyses were performed separately for each sex because there was a significant interactive effect of the $\log$ SMU Na/K and sex on the PAC. All $p$ values were two sided, and $p<0.05$ was regarded as statistically significant. Statistical analyses were performed using JMP version 14.3.0 (SAS Institute Inc., Cary, NC, USA) and R version 3.4.3 (R Foundation for Statistical Computing, Vienna, Austria).

\section{Results}

\section{Descriptive statistics of study participants}

Overall, 160 participants (108 men and 52 women) were eligible for inclusion in this study (Fig. 1). Participants' physical and lifestyle characteristics are shown in Table 1. The mean ages for men and women were 53.2 and 56.7 years, respectively. The mean $\mathrm{SMU} \mathrm{Na/K}$ values were 2.75 and $2.82 \mathrm{mmol} / \mathrm{mmol}$, and the mean PACs were 16.8 and $17.3 \mathrm{ng} / \mathrm{dL}$, respectively. No participants had an eGFR $<45$ $\mathrm{mL} / \mathrm{min} / 1.73 \mathrm{~m}^{2}$. When stratified by sex, women tended to have a healthier lifestyle, with greater frequencies of the intake of fruit, vegetables, and legumes, and a lower frequency of skipping breakfast. The proportions of participants who smoked and drank were higher in men than in women.

In the analysis stratified by PAC level, the urinary $\mathrm{Na}$ and SMU $\mathrm{Na} / \mathrm{K}$ were significantly lower and the PRA was significantly higher in the high-PAC group among men. The serum $\mathrm{K}$ level was significantly lower in the high-PAC group among women (Supplementary Table 1). 
Table 1 Physical and lifestyle characteristics of participants, 2017-2018

\begin{tabular}{|c|c|c|c|c|}
\hline & Total $(n=160)$ & Men $(n=108)$ & Women $(n=52)$ & $p$ value \\
\hline Age (years) & $54.3(8.0)$ & $53.2(8.1)$ & $56.7(7.4)$ & $<0.01$ \\
\hline Height (m) & $1.67(0.09)$ & $1.72(0.05)$ & $1.57(0.06)$ & $<0.01$ \\
\hline Body weight $(\mathrm{kg})$ & $70.6(13.9)$ & $75.0(12.6)$ & $61.5(11.9)$ & $<0.01$ \\
\hline Body mass index $\left(\mathrm{kg} / \mathrm{m}^{2}\right)$ & $25.2(3.9)$ & $25.3(3.8)$ & $24.9(4.2)$ & 0.53 \\
\hline Systolic blood pressure $(\mathrm{mmHg})$ & $148(12)$ & $146(12)$ & $151(11)$ & $<0.01$ \\
\hline Diastolic blood pressure $(\mathrm{mmHg})$ & $96(8)$ & $98(6)$ & $93(9)$ & $<0.01$ \\
\hline Urinary sodium $(\mathrm{mmol} / \mathrm{L})^{\mathrm{a}}$ & $147.6(50.4)$ & $150.2(52.7)$ & $142.2(45.3)$ & 0.32 \\
\hline Urinary potassium $(\mathrm{mmol} / \mathrm{L})^{\mathrm{a}}$ & $63.3(26.8)$ & $65.5(28.0)$ & $58.9(23.7)$ & 0.12 \\
\hline $\begin{array}{l}\text { Urinary sodium/potassium ratio }(\mathrm{mmol} / \\
\mathrm{mmol})^{\mathrm{a}}\end{array}$ & $2.77(1.55)$ & $2.75(1.60)$ & $2.82(1.46)$ & 0.78 \\
\hline Plasma aldosterone (ng/dL) & $17.0(5.4)$ & $16.8(5.5)$ & $17.3(5.3)$ & 0.59 \\
\hline Plasma renin activity $(\mathrm{ng} / \mathrm{mL} / \mathrm{hr})$ & $1.10(0.88)$ & $1.25(0.94)$ & $0.78(0.63)$ & $<0.01$ \\
\hline Serum potassium $(\mathrm{mmol} / \mathrm{L})$ & $4.2(0.3)$ & $4.3(0.3)$ & $4.2(0.3)$ & 0.11 \\
\hline Creatinine $(\mu \mathrm{mol} / \mathrm{L})$ & $70.2(14.3)$ & $76.9(11.9)$ & $56.4(7.0)$ & $<0.01$ \\
\hline $\mathrm{eGFR}\left(\mathrm{mL} / \mathrm{min} / 1.73 \mathrm{~m}^{2}\right)$ & $74.8(12.7)$ & $74.5(13.2)$ & $75.3(11.9)$ & 0.71 \\
\hline Sweating the day before the examination & $30(18.9)$ & $24(22.2)$ & $6(11.8)$ & 0.18 \\
\hline Sweating $\geq 5 /$ week & $18(11.3)$ & $13(12.0)$ & $5(9.6)$ & 0.85 \\
\hline Vegetables intake $\geq 1 /$ day & $132(82.5)$ & $82(75.9)$ & $50(96.2)$ & $<0.01$ \\
\hline Fruit intake $\geq 1 /$ day & $46(28.8)$ & $27(25.0)$ & $19(36.5)$ & 0.19 \\
\hline Legumes intake $\geq 1 /$ day & $60(37.5)$ & $34(31.5)$ & $26(50.0)$ & 0.04 \\
\hline Salty food intake $\geq 1 /$ day & $37(23.1)$ & $26(24.1)$ & $11(21.2)$ & 0.83 \\
\hline Skipping breakfast $\geq 3 /$ week & $31(19.4)$ & $26(24.1)$ & $5(9.6)$ & 0.05 \\
\hline Diabetes mellitus & $12(7.5)$ & $11(10.2)$ & $1(1.9)$ & 0.11 \\
\hline Current smoker & $24(15.0)$ & $23(21.3)$ & $1(1.9)$ & $<0.01$ \\
\hline Drinking & & & & $<0.01$ \\
\hline -Every day & 73 (45.6) & $60(55.6)$ & $13(25.0)$ & \\
\hline -Sometimes & $42(26.3)$ & $34(31.5)$ & $8(15.4)$ & \\
\hline -Rarely & $45(28.1)$ & $14(13.0)$ & $31(59.6)$ & \\
\hline
\end{tabular}

Continuous variables are described as mean (standard deviation); categorical variables are described as $n(\%)$ $e G F R$ estimated glomerular filtration rate

${ }^{a}$ Measured using second morning urine

Note: $p$ values are calculated using Fisher's exact test for dichotomic variables, $\chi^{2}$ test for multiple categorical variable (drinking status) and $t$-test for continuous variables

\section{Linear regression analyses}

Supplementary Table 2 shows the associations of the variables with the PAC in the entire study population. There was a significant interactive effect of the log SMU $\mathrm{Na} / \mathrm{K}$ and sex on the PAC. Table 2 shows the associations of the variables with the PAC stratified by sex. In the simple regression analysis, age, sweating $\geq 5 /$ week, and the $\log \mathrm{SMU} \mathrm{Na/K}$ were significantly associated with the PAC in men; the serum $\mathrm{K}$ level also tended to show an association. In multiple regression analysis, the serum $\mathrm{K}$ level, vegetable intake frequency $\geq 1 /$ day and the $\log$ $\mathrm{SMU} \mathrm{Na/K}$ were significantly associated with the PAC in men in models 1 and 2. Neither the $\log \mathrm{SMU} \mathrm{Na} / \mathrm{K}$ nor other variables were associated with the PAC in women.

\section{ROC curve analyses}

Participants with high PACs had values ranging from 24.3 to $39.2 \mathrm{ng} / \mathrm{dL}$. Figure 2 shows the ROC curves for the association of the SMU Na/K with a high PAC stratified by sex. The area under the ROC curve (AUC) for the relationship between the SMU Na/K and a high PAC was 0.77 (95\% CI: 0.59-0.95) in men and 0.64 (95\% CI: 0.36-0.93) in women. After age and serum $\mathrm{K}$ concentration were added, the AUC values became 0.80 (95\% CI: 0.65-0.96) and 0.82 (95\% CI: 0.69-0.95) in men and 0.64 (95\% CI: 0.36-0.93) and 0.80 (95\% CI: 0.61-1.00) in women, respectively. In men, a SMU Na/K $<1.0(\mathrm{mmol} / \mathrm{mmol})$ predicted a high PAC, with a sensitivity of $45.5 \%$, a specificity of $97.9 \%$, a positive predictive value of $71.4 \%$, and a negative predictive value of $94.1 \%$ (Table 3 ). The positive 


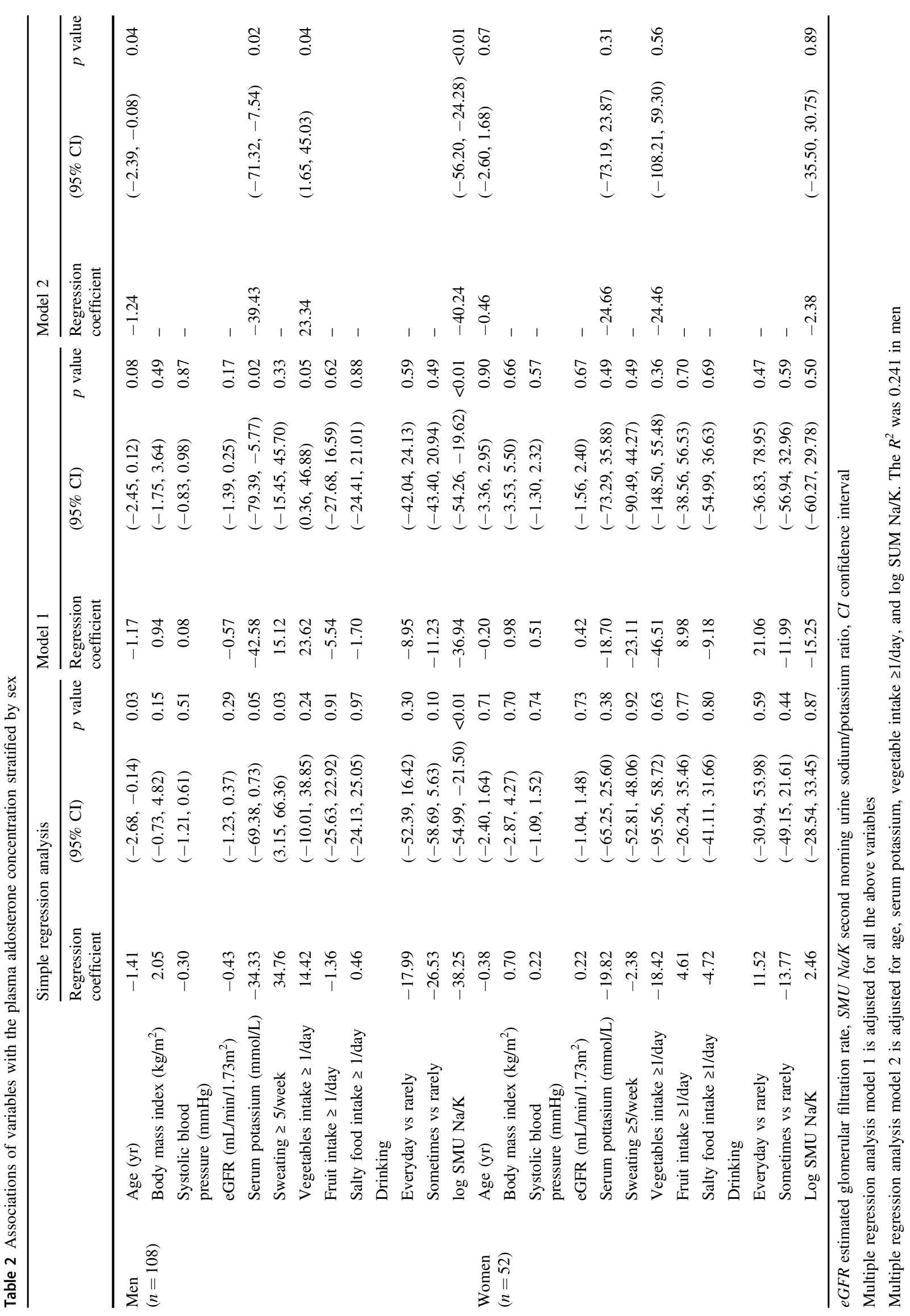




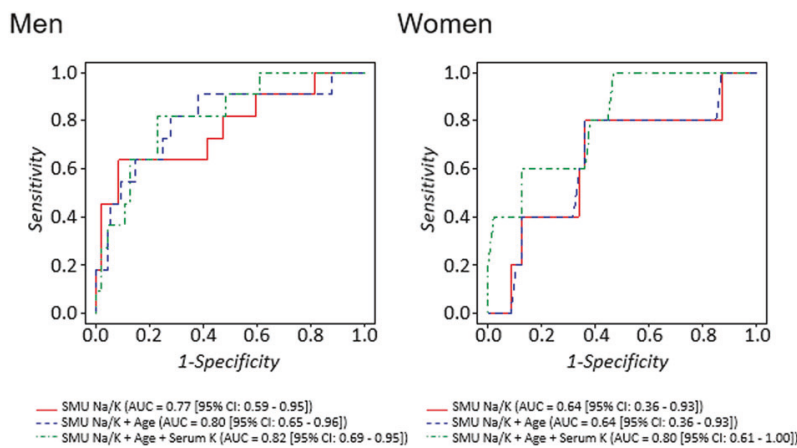

Fig. 2 ROC curve analysis of the association of the SMU Na/K with a high PAC ( 290 th percentile) stratified by sex (108 men and 52 women).The SMU Na/K was significantly associated with a high PAC in all models for men but only in the model including age and the serum $\mathrm{K}$ level (dashed line) in women. ROC curve receiver operating characteristic curve, SMU Na/K second morning urine sodium/potassium ratio, K potassium, PAC plasma aldosterone concentration, AUC area under the ROC curve, CI confidence interval

predictive values for a SMU $\mathrm{Na} / \mathrm{K}<2.0$ and $<3.0$ were much lower than that of a SMU Na/K $<1.0$.

The sensitivity analysis, from which participants with low sodium excretion $(\leq 10$ th percentile value) were excluded, showed that the AUCs for the relationships between the SMU Na/K and a high PAC were 0.67 (95\% CI: $0.46-0.87$ ) in men and 0.62 (95\% CI: 0.33-0.90) in women (Supplementary Figure).

\section{Discussion}

We proposed a screening method using the spot urinary $\mathrm{Na} / \mathrm{K}$ ratio to detect a high PAC among individuals with hypertension. In summary, the SMU Na/K had a significant inverse association with the PAC in hypertensive men but not in women. The AUC for the relationship between the SMU Na/K and a high PAC ( $\geq 90$ th percentile) was 0.77 (95\% CI: 0.59-0.95) in men and 0.64 (95\% CI: 0.36-0.93) in women. When the cutoff point was set to 1.0, the SMU $\mathrm{Na} / \mathrm{K}$ could predict a high PAC, with a sensitivity of $45.5 \%$, a specificity of $97.9 \%$, a positive predictive value of $71.4 \%$, and a negative predictive value of $94.1 \%$ in men. The positive predictive value was lower when the cutoff point was set at 2.0 and 3.0 than when it was set at 1.0. Thus, a low SMU Na/K could be a surrogate marker for a high PAC in men with hypertension. To the best of our knowledge, this is the first report to evaluate the association of the spot urinary $\mathrm{Na} / \mathrm{K}$ ratio with a high PAC.

The consideration of hypokalemia as a symptom of hyperaldosteronism in the diagnosis of primary aldosteronism has been proposed. However, fewer than half of patients with primary aldosteronism have hypokalemia, according to a recent international multicenter study [17].
A suboptimal method for detecting primary aldosteronism suggested in previous studies is the use of the SUSPPUP index, which is calculated as the serum sodium to urinary sodium ratio divided by the (serum potassium) [2] to urinary potassium ratio $[18,19]$. However, the reliability of the SUSPPUP index was unclear in a validation study [20]. Physiologically, the SUSPPUP is an index combining the urinary $\mathrm{Na} / \mathrm{K}$ ratio and serum $\mathrm{K}$ level because the serum $\mathrm{Na}$ level does not usually change as a result of secondary hypertension. Both the urinary $\mathrm{Na} / \mathrm{K}$ ratio and serum $\mathrm{K}$ level indicate a high PAC; thus, the SUSPPUP index can detect hyperaldosteronism but not primary aldosteronism or ARR. In the clinical setting, however, the independent assessment of the urinary $\mathrm{Na} / \mathrm{K}$ ratio and serum $\mathrm{K}$ level may be more feasible than the calculation of the SUSPPUP index, which is complex.

The urinary $\mathrm{Na} / \mathrm{K}$ ratio is easy to obtain, inexpensive, practical, and readily available in general outpatient clinics. It has been introduced as a biological marker of dietary quality because it indicates the balance between $\mathrm{Na}$ and $\mathrm{K}$ intake. Individuals who consume too much sodium and limited fruit and vegetables usually have a high urinary $\mathrm{Na} / \mathrm{K}$ ratio. Dietary intervention focusing on reducing blood pressure could lower the urinary $\mathrm{Na} / \mathrm{K}$ ratio in communitydwelling hypertensive men [21]. Previous reports have demonstrated associations of a higher $\mathrm{Na} / \mathrm{K}$ ratio with higher risks of hypertension [22], CVD [23, 24], and mortality $[24,25]$. In this context, a low urinary $\mathrm{Na} / \mathrm{K}$ ratio should be a favorable sign. However, some people with sustained or progressive hypertension have a low urinary $\mathrm{Na} / \mathrm{K}$ ratio even though they do not restrict their sodium intake or consume large quantities of fruit and vegetables. Our findings suggest that such individuals may have hyperaldosteronism if they are male. This insight may prevent clinicians from missing inappropriate aldosterone excretion among hypertensive men with a low $\mathrm{Na} / \mathrm{K}$ ratio.

In our study, we defined a high PAC as $\geq 90$ th percentile of PAC. Although the PAC cutoff point for identifying primary aldosteronism in Japan has been discussed in previous reports $[10,26]$, we could not set specific cutoff points for the following two reasons. (1) In this study, we aimed to detect hyperaldosteronism not just primary aldosteronism. (2) Prioritizing feasibility, we measured the PAC in a seated position without a 30-min rest. We suggest that hypertensive men with extremely low SMU Na/K (e.g., $<1.0 \mathrm{mmol} / \mathrm{mmol}$ ) should undergo detailed examinations for hyperaldosteronism.

There was a significant interactive effect of the log SMU $\mathrm{Na} / \mathrm{K}$ and sex on the PAC. Unlike in men, we found no significant association between the $\mathrm{SMU} \mathrm{Na/K}$ and the PAC in women. Although the reason for this is unclear, we considered several possible explanations, which are as follows. First, the sample size of women was smaller than that 
Table 3 Sensitivities and specificities of SMU $\mathrm{Na} / \mathrm{K}$ for high plasma aldosterone concentration ( $\geq 90$ th percentile) among men

\begin{tabular}{llll}
\hline & $\begin{array}{l}\text { SMU Na/K <1.0 } \\
(95 \% \text { confidence interval) }\end{array}$ & $\begin{array}{l}\text { SMU Na/K <2.0 } \\
(95 \% \text { confidence interval) }\end{array}$ & $\begin{array}{l}\text { SMU Na/K <3.0 } \\
(95 \% \text { confidence interval) }\end{array}$ \\
\hline Sensitivity & $45.5 \%(16.7-76.6)$ & $63.6 \%(30.8-89.1)$ & $90.9 \%(58.7-99.8)$ \\
Specificity & $97.9 \%(92.7-99.7)$ & $64.9 \%(54.6-74.4)$ & $40.2 \%(30.4-50.7)$ \\
PPV & $71.4 \%(29.0-96.3)$ & $17.1 \%(7.2-32.1)$ & $14.7 \%(7.3-25.4)$ \\
NPV & $94.1 \%(87.5-97.8)$ & $94.0 \%(85.4-98.3)$ & $97.5 \%(86.8-99.9)$ \\
\hline
\end{tabular}

$P P V$ positive predictive value, $N P V$ negative predictive value, $S M U N a / K$ second morning urine sodium/ potassium ratio of men. Thus, it might have been difficult to detect an association between the SMU Na/K and the PAC in women. Second, women consumed more vegetables and legumes than men, and these foods have high $\mathrm{K}$ levels (Table 1). It has been reported that a high frequency of the intake of fruit and vegetables is associated with a low urinary $\mathrm{Na} / \mathrm{K}$ ratio [27]. Vegetable intake might interact with the association between the SMU Na/K and the PAC; thus, this association might not be detectable in women. Third, the homeostasis of $\mathrm{Na}$ and $\mathrm{K}$ may differ according to sex. The urinary $\mathrm{Na}$ level was significantly lower in men with a high PAC than in those without a high PAC; the same observation was not made in women (Supplementary Table 1). Morimoto reported that the rate of sweating among women was lower than that among men who were exposed to heat [28]. Women might sweat less and excrete less $\mathrm{Na}$ via the skin surface than men; thus, the urinary $\mathrm{Na} / \mathrm{K}$ ratio might not become extremely low in women. Additionally, the serum $\mathrm{K}$ level in women with a high PAC was significantly lower than that in women without a high PAC (Supplementary Table 1). The AUC became significant when the serum $\mathrm{K}$ level was included in the model for women (Fig. 2). Although this could be a chance finding owing to the small sample size, a combination of the SMU Na/K and serum $\mathrm{K}$ level might improve the detection of hyperaldosteronism in women. Hypokalemia is a classic characteristic of hyperaldosteronism [29]; therefore, it is important to assess the serum K level together with the SMU Na/K. Further studies with large sample sizes are needed to test this hypothesis.

This study has several limitations. First, this was a smallsample study conducted at a single center. Thus, the feasible cutoff point for the SMU Na/K and the reasonable range for a high PAC for the detection of hyperaldosteronism should be validated in a future study. Second, our findings were obtained by a single measurement of the spot urinary $\mathrm{Na} / \mathrm{K}$ ratio. Although the SMU Na/K might be similar to the 24-h urine $\mathrm{Na} / \mathrm{K}$ ratio, the value in a single spot urine test includes random error compared with the 24-hour $\mathrm{Na} / \mathrm{K}$ ratio in individuals. Repeated measurements of the spot urine $\mathrm{Na} / \mathrm{K}$ ratio have been reported to provide a good estimate of the $24-\mathrm{h} \mathrm{Na} / \mathrm{K}$ ratio $[30,31]$. Considering the feasibility of implementation, repeated measurements of the $\mathrm{SMU} \mathrm{Na/K}$ with a self-monitoring device could improve the detection of hyperaldosteronism [32]. Further study is needed to evaluate the usefulness of applying these findings and methods. Third, the association between a low urinary $\mathrm{Na} / \mathrm{K}$ ratio and a high PAC may reflect compensation by the $\mathrm{PAC}$ in response to low sodium intake. Sodium restriction is usually recommended for hypertensive individuals to lower their blood pressure; however, biologically, this causes an increase in the PAC [33]. To validate how the present result was affected by "reverse causality," a reliable way of measuring individual sodium intake is essential. Unfortunately, we were unable to collect 24-hour urine (the gold-standard method of estimating individual sodium intake) in this study. However, we recruited participants with persistent hypertension to exclude individuals with a high PAC resulting from sodium restriction. We also performed a sensitivity analysis, from which we excluded participants who might have had low sodium intake, as determined using the Kawasaki equation [14] (Supplementary Figure). The results obtained were similar to those of the main analysis, although the AUC of the ROC curve was slightly smaller for men. However, it was difficult to remove the influence of sodium intake on PAC in the present study, and therefore, we should be aware of the possibility of reverse causality when interpreting the association between the urinary $\mathrm{Na} / \mathrm{K}$ ratio and the PAC.

\section{Conclusion}

The urinary $\mathrm{Na} / \mathrm{K}$ ratio in second morning urine was inversely associated with the PAC in hypertensive men but not in women. A low urinary $\mathrm{Na} / \mathrm{K}$ ratio could be a surrogate marker for the detection of a high PAC in hypertensive men.

Acknowledgements The authors wish to express their appreciation to participants in the health examinations at Takeda Hospital Medical Examination Center, as well as to the cooperating occupational nurse, Ms. Fumiko Nikaido, for her substantial contributions to participant recruitment and data collection. We also thank Hiroki Watanabe, Professor Emeritus, Urology, Kyoto Prefectural University of Medicine, for academic supervision. Finally, we thank Analisa Avila, ELS, of Edanz Group (https://en-a uthor-services.edanz.com/ac) for editing a draft of this manuscript. 
Funding This study was supported in part by a research grant from the Japan Society of Ningen Dock (No: 2018-1).

\section{Compliance with ethical standards}

Conflict of interest TI is currently an employee of Eli Lilly Japan; however, this work was conducted before he joined Eli Lilly Japan. This work is completely unrelated to the author's work with Eli Lilly Japan. The other authors declare no competing interests.

Ethics This study was conducted in accordance with the principles of the Declaration of Helsinki (seventh revision, 2013). The ethics committees of the Kyoto Prefectural University Institutional Review Board (No. 125, 2017) and Takeda Hospital Review Board (No. 1708, 2017) in Kyoto, Japan, approved the protocol. Written informed consent was obtained from all participants.

Publisher's note Springer Nature remains neutral with regard to jurisdictional claims in published maps and institutional affiliations.

Open Access This article is licensed under a Creative Commons Attribution 4.0 International License, which permits use, sharing, adaptation, distribution and reproduction in any medium or format, as long as you give appropriate credit to the original author(s) and the source, provide a link to the Creative Commons license, and indicate if changes were made. The images or other third party material in this article are included in the article's Creative Commons license, unless indicated otherwise in a credit line to the material. If material is not included in the article's Creative Commons license and your intended use is not permitted by statutory regulation or exceeds the permitted use, you will need to obtain permission directly from the copyright holder. To view a copy of this license, visit http://creativecommons. org/licenses/by/4.0/

\section{References}

1. Anderson GH Jr., Blakeman N, Streeten DH. The effect of age on prevalence of secondary forms of hypertension in 4429 consecutively referred patients. J Hypertens 1994; 12:609-15.

2. Omura M, Saito J, Yamaguchi K, Kakuta Y, Nishikawa T. Prospective study on the prevalence of secondary hypertension among hypertensive patients visiting a general outpatient clinic in Japan. Hypertens Res 2004;27:193-202.

3. Piaditis G, Markou A, Papanastasiou L, Androulakis II, Kaltsas G. Progress in aldosteronism: a review of the prevalence of primary aldosteronism in pre-hypertension and hypertension. Eur $\mathbf{J}$ Endocrinol 2015;172:R191-203.

4. Monticone S, D'Ascenzo F, Moretti C, Williams TA, Veglio F, Gaita F, et al. Cardiovascular events and target organ damage in primary aldosteronism compared with essential hypertension: a systematic review and meta-analysis. Lancet Diabetes Endocrinol 2018;6:41-50.

5. Young WF Jr. Diagnosis and treatment of primary aldosteronism: practical clinical perspectives. J Intern Med 2019;285:126-48.

6. Concistre A, Petramala L, Bisogni V, Mezzadri M, Olmati F, Saracino V, et al. Subclinical atherosclerosis due to increase of plasma aldosterone concentrations in essential hypertensive individuals. J Hypertens 2019;37:2232-9.

7. Tomaschitz A, Pilz S, Ritz E, Meinitzer A, Boehm BO, Marz W. Plasma aldosterone levels are associated with increased cardiovascular mortality: the Ludwigshafen Risk and Cardiovascular Health (LURIC) study. Eur Heart J 2010;31:1237-47.
8. Acelajado MC, Hughes ZH, Oparil S, Calhoun DA. Treatment of resistant and refractory hypertension. Circ Res 2019;124:1061-70.

9. Umemura S, Arima H, Arima S, Asayama K, Dohi Y, Hirooka Y, et al. The Japanese Society of Hypertension Guidelines for the Management of Hypertension (JSH 2019). Hypertens Res 2019;42:1235-481.

10. Nishikawa T, Omura M, Satoh F, Shibata H, Takahashi K, Tamura N, et al. Guidelines for the diagnosis and treatment of primary aldosteronism-the Japan Endocrine Society 2009. Endocr J 2011;58:711-21.

11. Okamoto R, Taniguchi M, Onishi Y, Kumagai N, Uraki J, Fujimoto $\mathrm{N}$, et al. Predictors of confirmatory test results for the diagnosis of primary hyperaldosteronism in hypertensive patients with an aldosterone-to-renin ratio greater than 20. The SHRIMP study. Hypertens Res 2019;42:40-51.

12. Kita T, Furukoji E, Sakae T, Kitamura K. Efficient screening of patients with aldosterone-producing adenoma using the ACTH stimulation test. Hypertens Res 2019;42:801-6.

13. Itoh $\mathrm{T}$, Abe $\mathrm{K}$, Gotoh $\mathrm{T}$, Yoshinaga $\mathrm{K}$. The screening of primary aldosteronism with PRA and urinary $\mathrm{Na} / \mathrm{K}$ after the furosemide test. Nihon Naika Gakkai Zasshi 1982;71:312-8. in Japanese.

14. Kawasaki T, Itoh K, Uezono K, Sasaki H. A simple method for estimating $24 \mathrm{~h}$ urinary sodium and potassium excretion from second morning voiding urine specimen in adults. Clin Exp Pharm Physiol 1993;20:7-14

15. Iwahori T, Ueshima H, Torii S, Saito Y, Kondo K, TanakaMizuno S, et al. Diurnal variation of urinary sodium-to-potassium ratio in free-living Japanese individuals. Hypertens Res 2017;40:658-64.

16. Matsuo S, Imai E, Horio M, Yasuda Y, Tomita K, Nitta K, et al. Revised equations for estimated GFR from serum creatinine in Japan. Am J Kidney Dis 2009;53:982-92.

17. Mulatero P, Stowasser M, Loh KC, Fardella CE, Gordon RD, Mosso L, et al. Increased diagnosis of primary aldosteronism, including surgically correctable forms, in centers from five continents. J Clin Endocrinol Metab 2004;89:1045-50.

18. Willenberg HS, Kolentini C, Quinkler M, Cupisti K, Krausch M, Schott M, et al. The serum sodium to urinary sodium to (serum potassium $)^{2}$ to urinary potassium (SUSPPUP) ratio in patients with primary aldosteronism. Eur J Clin Invest 2009;39:43-50.

19. Balas M, Zosin I, Maser-Gluth C, Hermsen D, Cupisti K, Schott $\mathrm{M}$, et al. Indicators of mineralocorticoid excess in the evaluation of primary aldosteronism. Hypertens Res 2010;33:850-6.

20. Steichen O, Blanchard A, Plouin PF. Assessment of serum sodium to urinary sodium divided by (serum potassium) ${ }^{2}$ to urinary potassium as a screening tool for primary aldosteronism. Eur $\mathbf{J}$ Clin Invest 2011:41:189-94.

21. Kitaoka K, Nagaoka J, Matsuoka T, Shigemura C, Harada K, Aoi $\mathrm{W}$, et al. Dietary intervention with cooking instructions and selfmonitoring of the diet in free-living hypertensive men. Clin Exp Hypertens 2013;35:120-7.

22. Intersalt Cooperative Research Group. Intersalt: an international study of electrolyte excretion and blood pressure. Results for $24 \mathrm{~h}$ urinary sodium and potassium excretion. Intersalt Cooperative Research Group. BMJ 1988;297:319-28.

23. Cook NR, Obarzanek E, Cutler JA, et al. Joint effects of sodium and potassium intake on subsequent cardiovascular disease: the trials of hypertension prevention follow-up study. Arch Intern Med 2009;169:32-40.

24. Okayama A, Okuda N, Miura K, Okamura T, Hayakawa T, Akasaka $\mathrm{H}$, et al. Dietary sodium-to-potassium ratio as a risk factor for stroke, cardiovascular disease and all-cause mortality in Japan: the NIPPON DATA80 cohort study. BMJ Open. 2016;6: e011632.

25. Yang Q, Liu T, Kuklina EV, Flanders WD, Hong Y, Gillespie C, et al. Sodium and potassium intake and mortality among US adults: 
prospective data from the Third National Health and Nutrition Examination Survey. Arch Intern Med 2011;171:1183-91.

26. The Writing Committee of The Japanese Society of Hypertension (eds). Guidelines for the Management of Hypertension 2019 (JSH2019). Tokyo: Life Science Publishing Co., Ltd. 2019.

27. Yamashita M, Tabara Y, Higo Y, Setoh K, Kawaguchi T, Takahashi $\mathrm{Y}$, et al. Association between socioeconomic factors and urinary sodium-to-potassium ratio: the Nagahama Study. Hypertens Res 2018;41:973-80.

28. Morimoto T, Slabochova Z, Naman RK, Sargent F 2nd. Sex differences in physiological reactions to thermal stress. J Appl Physiol 1967;22:526-32.

29. Gruber S, Beuschlein F Hypokalemia and the prevalence of primary aldosteronism. Horm Metab Res. 2020 https://doi.org/10.1055/a$1134-4980$.

30. Iwahori T, Ueshima H, Torii S, Saito Y, Fujiyoshi A, Ohkubo T, et al. Four to seven random casual urine specimens are sufficient to estimate 24-h urinary sodium/potassium ratio in individuals with high blood pressure. J Hum Hypertens 2016;30:328-34.

31. Iwahori T, Ueshima H, Miyagawa N, Ohgami N, Yamashita H, Ohkubo T, et al. Six random specimens of daytime casual urine on different days are sufficient to estimate daily sodium/potassium ratio in comparison to 7-day 24-h urine collections. Hypertens Res 2014;37:765-71.

32. Iwahori T, Ueshima H, Ohgami N, Yamashita H, Miyagawa N, Kondo $\mathrm{K}$, et al. Effectiveness of a self-monitoring device for urinary sodium-to-potassium ratio on dietary improvement in freeliving adults: a randomized controlled trial. $\mathrm{J}$ Epidemiol 2018;28:41-47.

33. Graudal NA, Hubeck-Graudal T, Jurgens G. Effects of low sodium diet versus high sodium diet on blood pressure, renin, aldosterone, catecholamines, cholesterol, and triglyceride. Cochrane DB Syst Rev 2017;4:Cd004022. 